\title{
Cystatin C- and Creatinine-Based Estimates of Glomerular Filtration Rate in Dapagliflozin Phase 3 Clinical Trials
}

\author{
Christian Mende $\cdot$ Arie Katz
}

To view enhanced content go to www.diabetestherapy-open.com

Received: December 15, 2015 / Published online: February 22, 2016

(C) The Author(s) 2016. This article is published with open access at Springerlink.com

\section{ABSTRACT}

Introduction: To compare estimated glomerular filtration rate measured by serum creatinine (eGFRcr) and serum cystatin C (eGFRcys) in patients with type 2 diabetes mellitus from dapagliflozin clinical trials.

Methods: Post hoc analysis of data pooled from 9 phase 3, randomized, placebo-controlled, 24-week trials of dapagliflozin. The correlation between eGFRcr and eGFRcys was modeled by a simple linear regression. The proportions of patients with eGFR 30 to $<60$ and $\geq 60 \mathrm{~mL} /$ $\mathrm{min} / 1.73 \mathrm{~m}^{2}$ based on creatinine versus cystatin $\mathrm{C}$ were compared.

A. Katz, AstraZeneca, Fort Washington, PA, USA: At the time of this research.

Electronic supplementary material The online version of this article (doi:10.1007/s13300-016-0158-y) contains supplementary material, which is available to authorized users.

C. Mende $(\varangle)$

University of California at San Diego, La Jolla, CA, USA

e-mail: cmende4730@aol.com

A. Katz

AstraZeneca, Fort Washington, PA, USA
Results: Of 4745 total patients, 4294 (90.5\%) had serum cystatin $C$ data available for calculation of eGFRcys. The correlation between eGFRcr and eGFRcys was poor $\left(R^{2}=30 \%\right)$. Of patients with eGFRcr 30 to $<60 \mathrm{~mL} / \mathrm{min} / 1.73 \mathrm{~m}^{2}, 66 \%$ had $\mathrm{eGFR} \geq 60$ when recalculated based on cystatin $\mathrm{C}$. Among patients with eGFRcr $\geq 60 \mathrm{~mL} / \mathrm{min} / 1.73 \mathrm{~m}^{2}$, $95.8 \%$ had eGFR $\geq 60$ when estimated using cystatin C. Decreases in $\mathrm{HbA}_{1 \mathrm{c}}$, body weight, and systolic blood pressure with dapagliflozin were similar among patient subgroups defined by either eGFR estimate and were statistically significant and clinically meaningful with dapagliflozin $10 \mathrm{mg} /$ day in most subgroups.

Conclusion: The correlation between eGFRcr and eGFRcys was poor. Renal function assessed by eGFRcr may be underestimated, and some patients may be misdiagnosed with chronic kidney disease and/or unjustifiably deemed ineligible for certain antidiabetes medications. This is in consonance with guidelines suggesting using eGFRcys as a confirmatory measure when eGFRcr is between 45 and $<60 \mathrm{~mL} / \mathrm{min} / 1.73 \mathrm{~m}^{2}$ with no evidence of kidney damage and/or in other situations where eGFRcr may be unreliable. 
Funding: AstraZeneca.

Keywords: Chronic kidney disease; Dapagliflozin; Glomerular filtration; GFR; Serum creatinine; Serum cystatin C; Sodium-glucose cotransporter; Type 2 diabetes

\section{INTRODUCTION}

Patients with diabetes have an increased risk of chronic kidney disease (CKD) [1], defined as an estimated glomerular filtration rate (eGFR) of $<60 \mathrm{~mL} / \mathrm{min} / 1.73 \mathrm{~m}^{2}$ or an albumin/creatinine ratio $>30 \mathrm{mg} / \mathrm{g}$ for more than 3 months [2]. The prevalence of CKD among patients with diabetes in the National Health and Nutrition Examination Survey (NHANES) from 2007 to 2012 was $\sim 40 \%$, and $\sim 20 \%$ of the diabetes population had an eGFR $<60 \mathrm{~mL} / \mathrm{min} / 1.73 \mathrm{~m}^{2}$ [3]. Diabetes is also the major cause of end-stage renal disease (ESRD) [3]. Because GFR is the best overall measure of kidney function [2], its accurate assessment is important for the diagnosis of CKD and for drug dosing considerations; many drugs, including some antidiabetes medications, are eliminated by the kidney and require dose adjustment in CKD or depend on kidney function for efficacy [4].

Glomerular filtration rate can be directly measured by determining the clearance of exogenous filtration markers such as iothalamate, iohexol, or inulin [5]. However, these methods are time consuming, expensive, and impractical for routine clinical use. Therefore, estimates of GFR based on serum concentrations of the endogenous filtration marker creatinine are commonly used to assess kidney function. Serum creatinine concentrations may be affected by several factors, including age, sex, ethnicity, muscle mass, dietary protein intake, and overall health $[6,7]$. Various creatinine-based equations to assess GFR, most notably the Modification of Diet in Renal Disease (MDRD) and CKD Epidemiology Collaboration (CKD-EPI) [2], have been developed to account for such factors. These equations may not be suitable in all patients and may underestimate GFR in individuals with eGFR $60-80 \mathrm{~mL} / \mathrm{min} / 1.73 \mathrm{~m}^{2}$ [8], and notably in patients with eGFR 45 to $<60 \mathrm{~mL} / \mathrm{min} / 1.73 \mathrm{~m}^{2}$ [9].

Because of the limitations of creatinine-based eGFR (eGFRcr), estimates of GFR based on cystatin C (eGFRcys) have been proposed as an alternative, less variable measure of eGFR [10]. Cystatin C is a cysteine protease inhibitor that is constitutively produced by all nucleated cells, filtered by the glomerulus, and reabsorbed by tubular cells, but not secreted by the renal tubules [11]. Cystatin $\mathrm{C}$ is less influenced than creatinine by the individual factors noted above, although small effects of diabetes, inflammation, body mass index, thyroid status, and steroid therapy on serum cystatin $\mathrm{C}$ concentrations have been described $[2,12]$. Estimates of GFR based on cystatin C appear to correlate better than ones based on creatinine with morbidity and mortality in diverse patient populations, including those with CKD [9]. In addition, serum cystatin C concentration may be a better predictor of progression to ESRD than serum creatinine in individuals with type 2 diabetes and albuminuria [13]. Based on these considerations, the Kidney Disease: Improving Global Outcomes (KDIGO) guidelines suggest using eGFRcys as a confirmatory measure when eGFRcr is between 45 and $<60 \mathrm{~mL} / \mathrm{min} / 1.73 \mathrm{~m}^{2}$ in patients with no evidence of kidney damage and/or in other situations in which eGFRcr may be unreliable [2]. 
Accurate estimates of GFR are important not only for diagnosis and staging of CKD but also for dose adjustment of drugs that are eliminated by the kidneys, or for administration of drugs whose action depends on renal function. Sodium-glucose cotransporter 2 (SGLT2) inhibitors, the newest class of antidiabetes agents, reduce plasma glucose concentrations by inhibiting the reabsorption of glucose in the kidney and increasing glucose excretion in the urine [14]. SGLT2 inhibitor efficacy depends on the ability of the kidneys to filter glucose and thus declines with reduced GFR [15-17]. For example, dapagliflozin should not be used in patients with eGFR $<60 \mathrm{~mL} / \mathrm{min} / 1.73 \mathrm{~m}^{2}$ owing to reduced efficacy and safety considerations [18].

The objective of this analysis was to compare assessments of eGFRcr and eGFRcys in patients with type 2 diabetes pooled from dapagliflozin phase 3 trials. The results of this analysis may have important implications for the diagnosis of CKD and the eligibility of patients for treatment with antidiabetes drugs that are limited by renal function.

\section{METHODS}

This was a post hoc analysis that included data pooled from 9 dapagliflozin phase 3, randomized, double-blind, placebo-controlled, 24-week studies in adult patients ( $\geq 18$ years of age) with type 2 diabetes mellitus. Dapagliflozin 5 or $10 \mathrm{mg} /$ day or placebo was administered as monotherapy in treatment-naive patients (ClinicalTrials.gov identifier, NCT00528372) [19]; as initial combination therapy with metformin (NCT00859898) [20]; and as add-on to the following: metformin (NCT00528879 and NCT00855166) [21, 22], glimepiride (NCT00680745) [23], sitagliptin \pm metformin
(NCT00984867) [24], insulin \pm up to 2 other antidiabetes medications (NCT00673231) [25], usual care in patients with cardiovascular disease (NCT01042977) [26], and usual care in patients with cardiovascular disease and hypertension (NCT01031680) [27]. Study designs, inclusion and exclusion criteria, and primary findings for these 9 studies have been previously reported in detail [19-27]. This article is based on previously conducted studies and does not involve any new studies of human or animal subjects performed by any of the authors. The original clinical trials were designed and monitored in accordance with the ethical principles of Good Clinical Practice as defined by the International Conference on Harmonisation and Declaration of Helsinki. Institutional review boards or ethics committees at each study site approved the protocols, and all patients gave written informed consent.

Creatinine-based eGFR was calculated using the MDRD formula: eGFR $\left(\mathrm{mL} / \mathrm{min} / 1.73 \mathrm{~m}^{2}\right)=$ $175 \times(\text { serum creatinine, } \mathrm{mg} / \mathrm{L})^{-1.154} \times$ $(\text { age })^{-0.203} \times(0.742$ if female $) \times(1.212$ if African American) [28]. Cystatin C-based eGFR was calculated as eGFR $\left(\mathrm{mL} / \mathrm{min} / 1.73 \mathrm{~m}^{2}\right)=$ $76.7 \times(\text { serum cystatin, } \mathrm{mg} / \mathrm{L})^{-1.19}[10]$.

The correlation between eGFRcr and eGFRcys was modeled by a simple linear regression. The strength of the relationship between these 2 variables was estimated by the coefficient of determination, $R^{2}$, calculated from the linear regression analysis and presented as a percentage $\left(R^{2} \%=R^{2} \times 100\right)$.

Changes from baseline in $\mathrm{HbA}_{1 \mathrm{c}}$, body weight, and systolic blood pressure (SBP) at week 24 (last observation carried forward) in all patients who received study medication and had at least 1 post-baseline assessment were analyzed using an analysis of covariance model in which treatment, subgroup, and study were 
included in the model as factors. Treatment by subgroup was included as an interaction term; and baseline value and study by baseline value were included as covariates for each GFR estimation method. $P$ values (without multiplicity adjustment) for treatment comparisons were estimated from respective $t$ tests. All statistical analyses were performed using SAS procedures (SAS version 9.2, SAS Institute, Cary, NC, USA).

Safety and tolerability based on adverse events (AEs), serious AEs (SAEs), hypoglycemia, laboratory abnormalities, and vital signs were assessed in all patients who received study medication. Hypoglycemia events excluded data after rescue treatment. Major hypoglycemia was defined as a symptomatic episode requiring third-party assistance owing to severe impairment of consciousness or behavior, with plasma glucose $<3.0 \mathrm{mmol} / \mathrm{L}$ and prompt recovery with glucose or glucagon administration. Minor hypoglycemia was a symptomatic or asymptomatic episode with plasma glucose $<3.5 \mathrm{mmol} / \mathrm{L}$. Other hypoglycemia was a suggestive episode that was reported but did not meet the criteria for major or minor episodes.

\section{RESULTS}

A total of 4745 patients were included in this analysis (Table 1); 4294 (90.5\%) had serum cystatin C data available for calculation of eGFRcys. Most patients were white and there were approximately equal numbers of men and women. In the pooled data set, $12.4 \%$ (589/ 4745 ) of patients had baseline eGFRcr 30 to $<60 \mathrm{~mL} / \mathrm{min} / 1.73 \mathrm{~m}^{2}$. These patients were generally older, with a longer duration of diabetes, and with higher body weight and body mass index than those with eGFRcr $\geq 60 \mathrm{~mL} / \mathrm{min} / 1.73 \mathrm{~m}^{2}$.
In contrast, $7.7 \%(332 / 4294)$ of patients with available cystatin $\mathrm{C}$ data had baseline eGFRcys 30 to $<60 \mathrm{~mL} / \mathrm{min} / 1.73 \mathrm{~m}^{2}$ (Table 2). Of patients with moderate renal impairment (CKD stage 3, eGFR 30 to $<60 \mathrm{~mL} / \mathrm{min} /$ $1.73 \mathrm{~m}^{2}$ ) [2] based on creatinine, $66 \%$ had eGFR $\geq 60 \mathrm{~mL} / \mathrm{min} / 1.73 \mathrm{~m}^{2}$ when recalculated based on cystatin C. Among patients with eGFRcr $\geq 60 \mathrm{~mL} / \mathrm{min} / 1.73 \mathrm{~m}^{2}, \quad 95.8 \%$ had eGFRcys $\geq 60 \mathrm{~mL} / \mathrm{min} / 1.73 \mathrm{~m}^{2}$. Results were similar in women and men. The overall correlation between eGFRcr and eGFRcys was poor, $R^{2}=30 \%$ (Fig. 1 ).

Adjusted mean changes from baseline in $\mathrm{HbA}_{1 \mathrm{c}}$, body weight, and SBP with dapagliflozin were generally similar within patient subgroups stratified by either creatinine- or cystatin C-based estimates of GFR (Fig. 2). Statistically significant and clinically meaningful changes with dapagliflozin $10 \mathrm{mg} /$ day versus placebo were observed in most subgroups. Changes from baseline in $\mathrm{HbA}_{1 \mathrm{c}}$ appeared to be larger in patients with $\mathrm{eGFR} \geq 60 \mathrm{~mL} / \mathrm{min} / 1.73 \mathrm{~m}^{2}$ than in those with eGFR 30 to $<60 \mathrm{~mL} / \mathrm{min} / 1.73 \mathrm{~m}^{2}$, regardless of GFR estimation method.

Within the eGFR ranges estimated by either creatinine or cystatin $\mathrm{C}$, the proportion of patients with $\geq 1 \quad \mathrm{AE}$ was similar between placebo and dapagliflozin-treated patients (Table 3). A greater proportion of patients with eGFR 30 to $<60 \mathrm{~mL} / \mathrm{min} / 1.73 \mathrm{~m}^{2}$ experienced AEs than those with eGFR $\geq 60 \mathrm{~mL} / \mathrm{min} /$ $1.73 \mathrm{~m}^{2}$. Similar findings were observed for the proportion of patients with $\geq 1$ SAE and with $\geq 1$ AE leading to discontinuation. Genital infections were more frequent with dapagliflozin compared with placebo regardless of eGFR group or estimation method, whereas urinary tract infections were more common in patients with eGFR 30 to $<60 \mathrm{~mL} / \mathrm{min} / 1.73 \mathrm{~m}^{2}$ than in those 


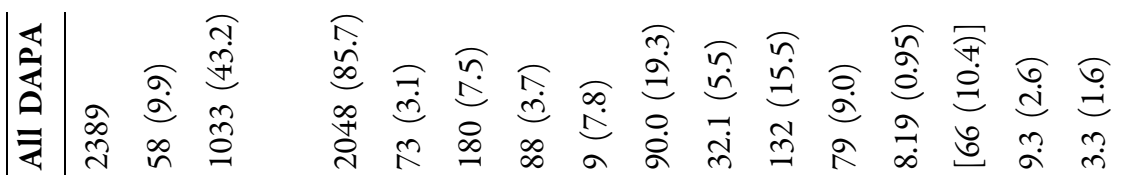

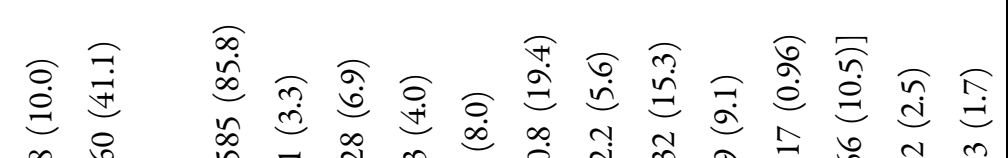

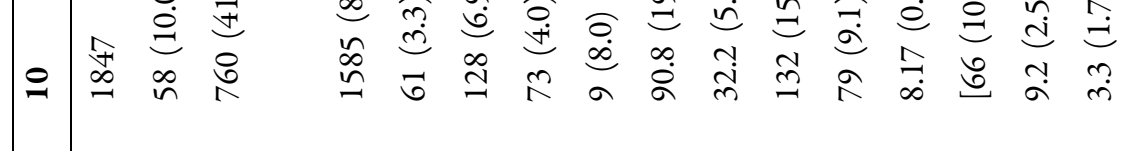

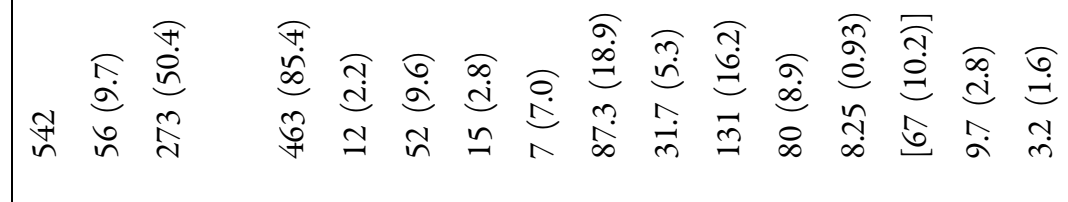

\section{$\widehat{\hat{\theta}}$}

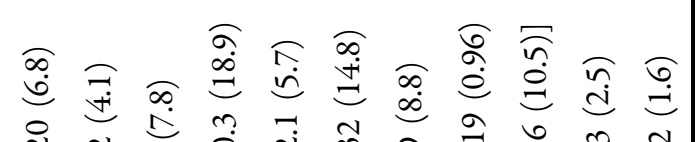

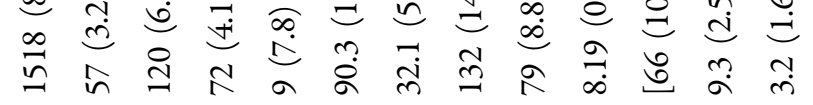

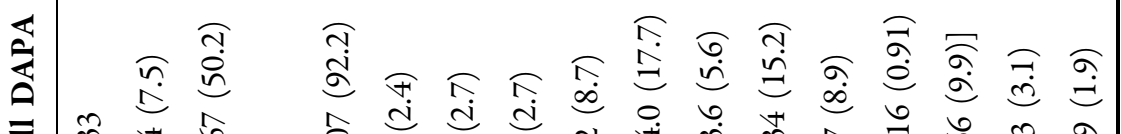

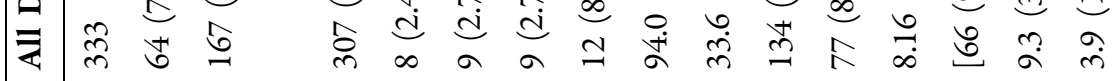

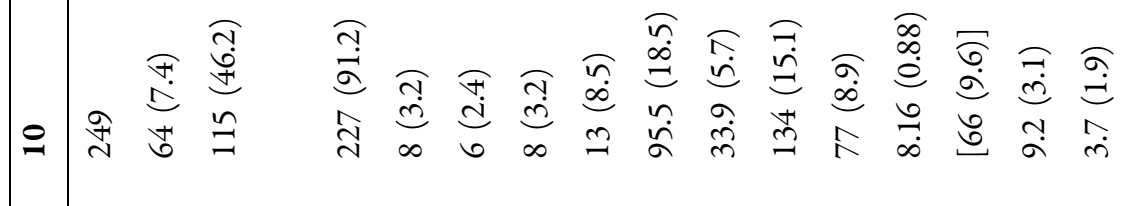
蛋

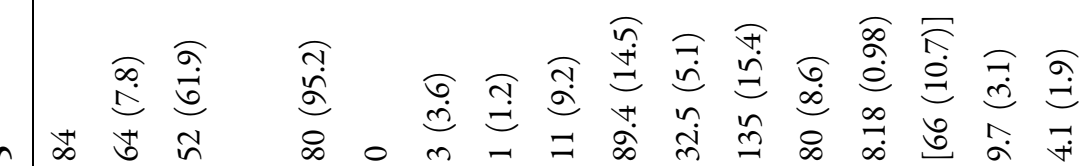

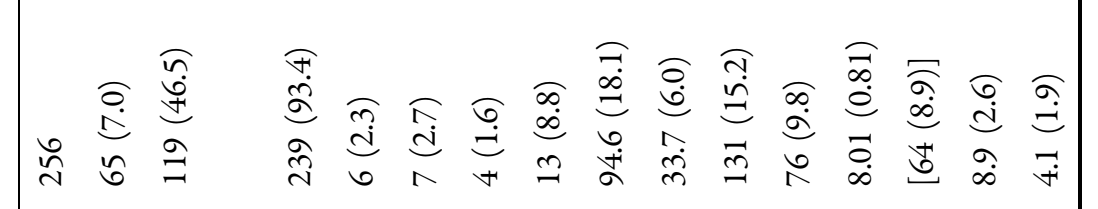




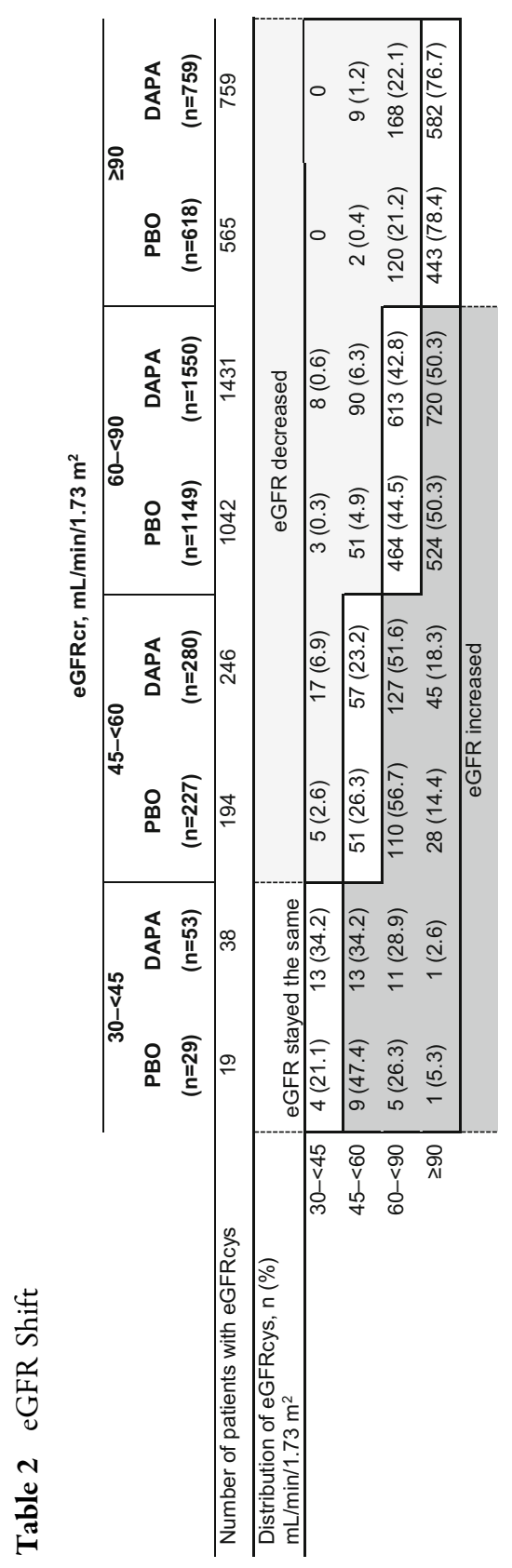

with eGFR $\geq 60 \mathrm{~mL} / \mathrm{min} / 1.73 \mathrm{~m}^{2}$ in both the dapagliflozin and placebo groups. A greater proportion of patients with eGFR 30 to $<60 \mathrm{~mL} / \mathrm{min} / 1.73 \mathrm{~m}^{2}$ compared with those with eGFR $\geq 60 \mathrm{~mL} / \mathrm{min} / 1.73 \mathrm{~m}^{2}$ had renal AEs that included renal impairment, renal failure, GFR decrease, or blood creatinine or cystatin C increase. Within the 30 to $<60 \mathrm{~mL} / \mathrm{min} / 1.73 \mathrm{~m}^{2}$ group, renal AEs were more frequent with dapagliflozin than with placebo. AEs of hypovolemia (hypotension, dehydration, or hypovolemia) were uncommon and similar across all treatment and eGFR groups. The incidence of hypoglycemia was variable across groups but appeared to be higher in patients with eGFR 30 to $<60 \mathrm{~mL} / \mathrm{min} / 1.73 \mathrm{~m}^{2}$; events of major hypoglycemia were rare $(\leq 0.1 \%)$ across eGFR and treatment groups.

\section{DISCUSSION}

Accurate assessment of GFR is essential for the diagnosis of CKD [2] and for use in dose adjustment of several antidiabetes drugs [4]. In this analysis, $66 \%$ of patients with type 2 diabetes classified as having moderate renal impairment at baseline (CKD stage 3) when GFR was estimated based on serum creatinine had mild or no renal impairment when GFR was estimated based on serum cystatin C. Such patients would be erroneously classified with $\mathrm{CKD}$, with associated treatment and healthcare implications, and would be ineligible to receive antidiabetes medications that are GFR-limited, such as SGLT2 inhibitors and metformin [29], or, alternatively, would be prescribed lower, possibly less effective doses of certain antidiabetes medications that require dose adjustments based on GFR, such as some sulfonylureas, dipeptidyl peptidase-4 inhibitors, and glucagon-like peptide-1 receptor agonists [4]. 


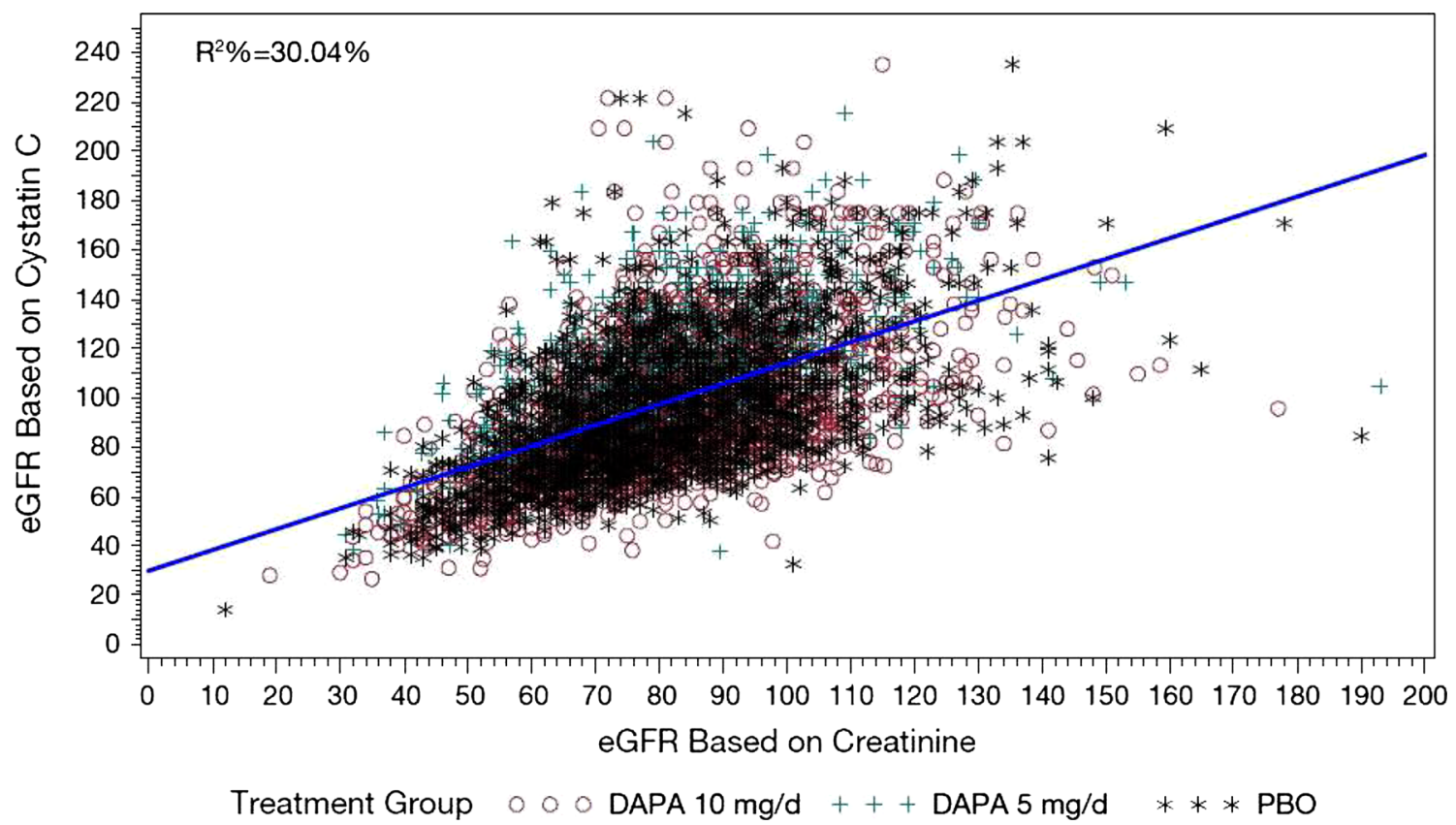

Fig. 1 Correlation of baseline eGFRcr vs eGFRcys. DAPA dapagliflozin, eGFR estimated glomerular filtration rate, $e G F R c r$ creatinine-based eGFR, eGFRcys cystatin C-based eGFR, $P B O$ placebo, $R^{2}$ coefficient of determination

Equations to estimate GFR based on serum creatinine, including MDRD and CKD-EPI, may not be accurate in all patients and may underestimate GFR, particularly in patients with eGFR 45 to $<60 \mathrm{~mL} / \mathrm{min} / 1.73 \mathrm{~m}^{2}$ [9]. A number of analyses have suggested that eGFR based on serum cystatin $\mathrm{C}$ may be a more accurate measure of GFR than creatinine-based estimates in diverse patient populations [30-32], including those with diabetes [13, 33-35]. In addition, eGFRcys compared with eGFRcr may better predict health outcomes, including: all-cause and cardiovascular mortality in individuals with diabetes [36], cardiovascular events in patients with diabetes and CKD (defined as eGFR $<60 \mathrm{~mL} / \mathrm{min}$ / $1.73 \mathrm{~m}^{2}$ ) [37], and overall mortality in older individuals (mean age 78 years) with diabetes [38]. Because cystatin $C$ is less influenced than creatinine by factors other than GFR and because eGFRcys appears to better estimate GFR in the range of 45 to $<60 \mathrm{~mL} / \mathrm{min} /$
$1.73 \mathrm{~m}^{2}$, clinical practice guidelines suggest that eGFRcys be used as confirmation of eGFRcr or in combination with eGFRcr to better estimate GFR in such individuals $[2,9$, 39].

In our pooled analysis of data from adult patients with type 2 diabetes who participated in dapagliflozin clinical trials, approximately two-thirds of patients with eGFRcr 30 to $<60 \mathrm{~mL} / \mathrm{min} / 1.73 \mathrm{~m}^{2}$ had eGFR $\geq 60 \mathrm{~mL} / \mathrm{min} /$ $1.73 \mathrm{~m}^{2}$ when measured by cystatin $\mathrm{C}$. This finding is consistent with observations in other studies. For example, in a meta-analysis of 16 studies in which measurements of eGFRcr and eGFRcys were available in populations with a broad range of kidney function $(N=93,710)$, $42 \%$ of individuals with eGFRcr 45 to $<60 \mathrm{~mL} /$ $\mathrm{min} / 1.73 \mathrm{~m}^{2}$ had eGFR $\geq 60 \mathrm{~mL} / \mathrm{min} / 1.73 \mathrm{~m}^{2}$ when measured by cystatin $\mathrm{C}$ [9]. Also, eGFRcys, alone or in combination with eGFRcr, showed a better correlation between eGFR category and risk of death and ESRD than 

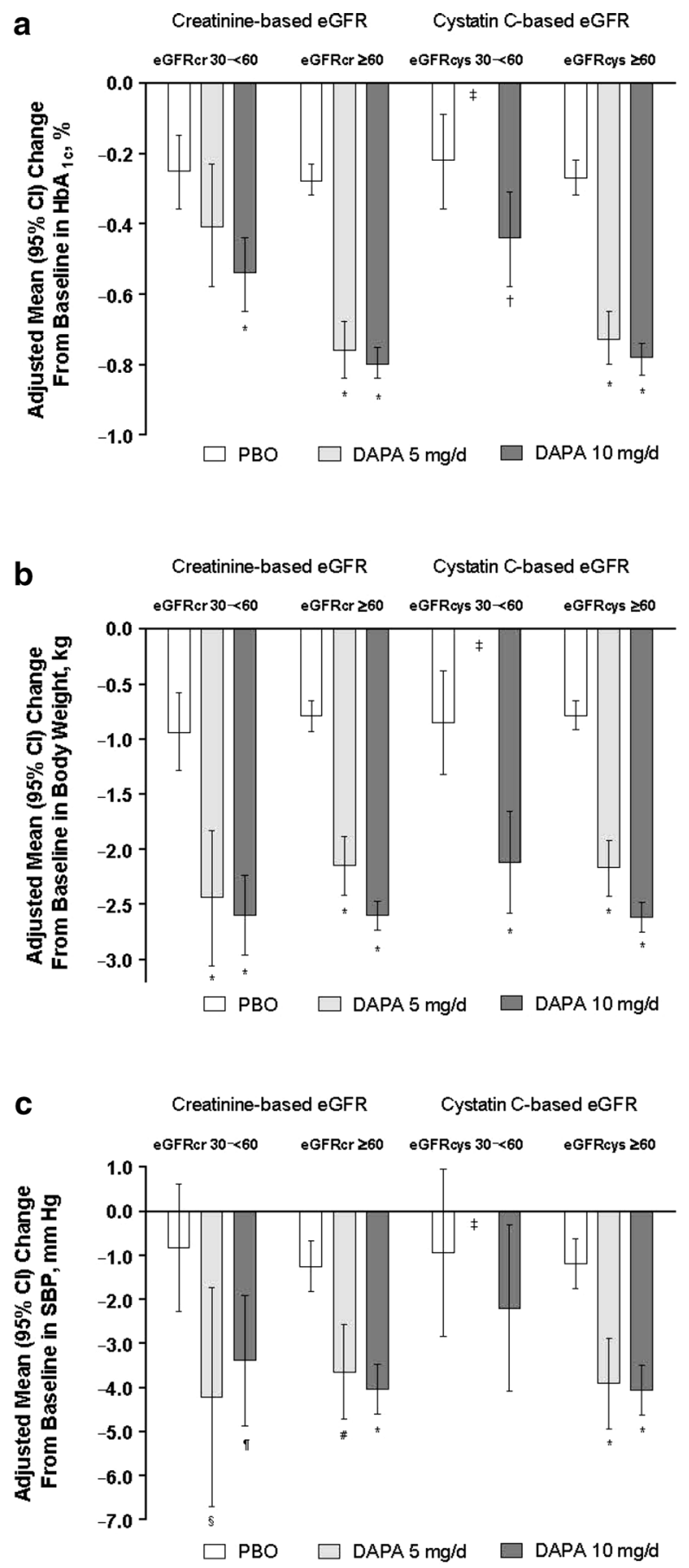

eGFRcr. In another analysis of participants $(N=11,909)$ in the Multi-Ethnic Study of Atherosclerosis and the Cardiovascular Health Study, only $21-56 \%$ of individuals (depending
4 Fig. 2 Adjusted mean change from baseline in $\operatorname{HbA}_{1 \mathrm{c}}(\mathbf{a})$, body weight (b), and seated SBP (c) stratified by creatinine-based and cystatin C-based eGFR. CI confidence interval, $D A P A$ dapagliflozin, eGFR estimated glomerular filtration rate, eGFRcr creatinine-based eGFR, eGFRcys cystatin C-based eGFR, $P B O$ placebo, SBP systolic blood pressure. ${ }^{*} P<0.0001,{ }^{\dagger} P=0.015$, ${ }^{\star}$ Data not shown, $n=8-9,{ }^{\S} P=0.021,{ }^{\circledR} P=0.013,{ }^{\#} P=$ 0.0002 versus placebo

on age) with eGFRcr $<60 \mathrm{~mL} / \mathrm{min} / 1.73 \mathrm{~m}^{2}$ had GFR $<60 \mathrm{~mL} / \mathrm{min} / 1.73 \mathrm{~m}^{2}$ when measured by cystatin C [32], and eGFRcys was a better predictor of death, cardiovascular disease, heart failure, and ESRD than was eGFRcr in individuals with CKD.

Some studies, however, have reported less discordant results between eGFRcr and eGFRcys. For example, in 3 cohorts of patients with type 1 or 2 diabetes $(N=1165), 65-77 \%$ of patients with eGFRcr 30 to $<60 \mathrm{~mL} / \mathrm{min} / 1.73 \mathrm{~m}^{2}$ had the same range of eGFR when measured with cystatin C; $4-14 \%$ of patients with eGFRcr 30 to $<60 \mathrm{~mL} / \mathrm{min} / 1.73 \mathrm{~m}^{2}$ had eGFRcys 60-89 $\mathrm{mL} / \mathrm{min} / 1.73 \mathrm{~m}^{2}$ [35].

In our analysis, changes from baseline in $\mathrm{HbA}_{1 \mathrm{c}}$ with dapagliflozin compared with placebo appeared greater in patients with eGFR $\geq 60 \mathrm{~mL} / \mathrm{min} / 1.73 \mathrm{~m}^{2}$ than in those with eGFR 30 to $<60 \mathrm{~mL} / \mathrm{min} / 1.73 \mathrm{~m}^{2}$, regardless of calculation method. This is consistent with the mechanism of action of SGLT2 inhibitors [14] and with published studies of dapagliflozin [15] and other SGLT2 inhibitors, in which the efficacy decreased with lower GFR [16, 17]. Changes in body weight and SBP were generally similar across the 2 eGFR ranges. The proportion of patients with AEs, including renal AEs, SAEs, and hypoglycemia, was greater in patients with eGFR 30 to $<60 \mathrm{~mL} / \mathrm{min} / 1.73 \mathrm{~m}^{2}$ compared with those with eGFR $\geq 60 \mathrm{~mL} / \mathrm{min} /$ $1.73 \mathrm{~m}^{2}$, perhaps reflecting the overall health status of these individuals. Occurrence of these AEs in patients with eGFR 30 to $<60 \mathrm{~mL} / \mathrm{min} /$ 


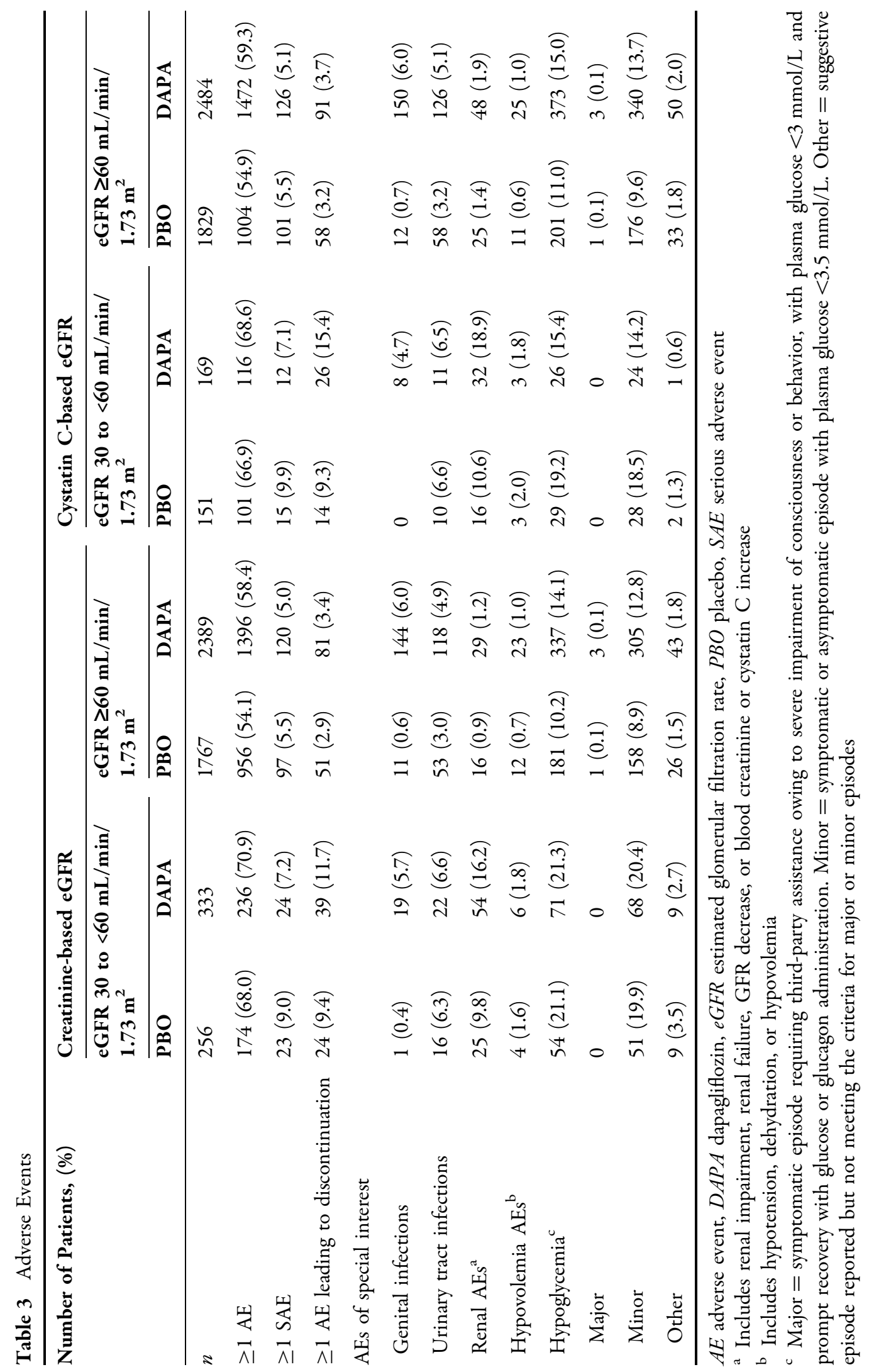


$1.73 \mathrm{~m}^{2}$ was similar between dapagliflozin and placebo, except for renal AEs, which were more frequent with dapagliflozin. Similar to other studies with dapagliflozin [40], genital infections were more frequent with dapagliflozin compared with placebo and occurred in similar proportions of patients across eGFR ranges.

In spite of the poor correlation between eGFRcr and eGFRcys and the finding that approximately two-thirds of patients diagnosed with CKD stage 3 by the former had only mild renal impairment based on the latter. The efficacy and safety profiles of dapagliflozin in this pooled analysis seemed unaffected by the GFR estimation method, suggesting that whereas many patients could have potentially benefited from being eligible to receive dapagliflozin based on eGFRcys, the risk profile in these patients would have remained unchanged.

Strengths of this analysis include a large study population with a range of type 2 diabetes disease duration and the use of data from prospective, randomized, placebo-controlled trials. An important limitation of this analysis was that the population of patients was relatively homogeneous, predominantly white, and 56-65 years of age. An additional limitation was the small proportion of patients with eGFR 30 to $<60 \mathrm{~mL} / \mathrm{min} / 1.73 \mathrm{~m}^{2}$. Whether these findings can be generalized to other races and age groups is unknown, but because serum cystatin $\mathrm{C}$ concentrations appear to be less affected by age and race than serum creatinine [12], eGFRcys may be a more accurate estimate of GFR in some patients.

\section{CONCLUSION}

The results of this analysis suggest that the correlation between eGFRcys and eGFRcr in patients with type 2 diabetes may be even poorer than previously reported in a broader population. Renal function as assessed by eGFRcr may be underestimated, and many patients may be misdiagnosed with CKD and/ or unjustifiably deemed ineligible to receive certain antidiabetes medications. These findings, together with existing data on correlation between eGFRcys and cardiovascular and renal outcomes, support recommendations that eGFRcys, alone or in combination with eGFRcr, be used when eGFRcr is in the range of 45 to $<60 \mathrm{~mL} / \mathrm{min} /$ $1.73 \mathrm{~m}^{2}$ and/or in other situations in which eGFRcr may be unreliable. The use of eGFRcys may provide a better estimate of GFR in patients with type 2 diabetes.

\section{ACKNOWLEDGMENTS}

Sponsorship for this study and article processing charges was funded by AstraZeneca, Fort Washington, PA, USA.

All named authors meet the International Committee of Medical Journal Editors (ICMJE) criteria for authorship for this manuscript, take responsibility for the integrity of the work as a whole, and have given final approval to the version to be published.

Medical writing support for the preparation of this manuscript was provided by Richard Edwards, PhD, and Janet Matsuura, PhD, from Complete Healthcare Communications, LLC (Chadds Ford, PA), with funding from AstraZeneca.

Disclosures. Christian Mende serves on the speaker bureau of AstraZeneca. Arie Katz was an employee of AstraZeneca at the time of this research. 
Compliance with Ethics Guidelines. This article is based on previously conducted studies, and does not involve any new studies of human or animal subjects performed by any of the authors.

Open Access. This article is distributed under the terms of the Creative Commons AttributionNonCommercial 4.0 International License (http://creativecommons.org/licenses/by-nc/4. $0 /$ ), which permits any noncommercial use, distribution, and reproduction in any medium, provided you give appropriate credit to the original author(s) and the source, provide a link to the Creative Commons license, and indicate if changes were made.

\section{REFERENCES}

1. Centers for Disease Control and Prevention. National chronic kidney disease fact sheet 2014 . 2014. http://www.cdc.gov/diabetes/pubs/pdf/ kidney_Factsheet.pdf. Accessed Dec 8, 2015.

2. KDIGO. clinical practice guideline for the evaluation and management of chronic kidney disease. Kidney Int. 2012;2013(3):1-150.

3. Saran R, Li Y, Robinson B, et al. US Renal Data System 2014 Annual Data Report: epidemiology of Kidney Disease in the United States. Am J Kidney Dis. 2015;65:A7.

4. Arnouts P, Bolignano D, Nistor I, et al. Glucose-lowering drugs in patients with chronic kidney disease: a narrative review on pharmacokinetic properties. Nephrol Dial Transplant. 2014;29:1284-300.

5. Stevens LA, Levey AS. Measured GFR as a confirmatory test for estimated GFR. J Am Soc Nephrol. 2009;20:2305-13.

6. Macisaac RJ, Premaratne E, Jerums G. Estimating glomerular filtration rate in diabetes using serum cystatin C. Clin Biochem Rev. 2011;32:61-7.

7. Shlipak MG, Mattes MD, Peralta CA. Update on cystatin C: incorporation into clinical practice. Am J Kidney Dis. 2013;62:595-603.
8. Murata K, Baumann NA, Saenger AK, Larson TS, Rule AD, Lieske JC. Relative performance of the MDRD and CKD-EPI equations for estimating glomerular filtration rate among patients with varied clinical presentations. Clin J Am Soc Nephrol. 2011;6:1963-72.

9. Shlipak MG, Matsushita K, Arnlov J, et al. Cystatin $C$ versus creatinine in determining risk based on kidney function. N Engl J Med. 2013;369:932-43.

10. Stevens LA, Coresh J, Schmid CH, et al. Estimating GFR using serum cystatin $\mathrm{C}$ alone and in combination with serum creatinine: a pooled analysis of 3,418 individuals with CKD. Am J Kidney Dis. 2008;51:395-406.

11. Ferguson MA, Waikar SS. Established and emerging markers of kidney function. Clin Chem. 2012;58:680-9.

12. Stevens LA, Schmid CH, Greene T, et al. Factors other than glomerular filtration rate affect serum cystatin C levels. Kidney Int. 2009;75:652-60.

13. Pavkov ME, Knowler WC, Hanson RL, et al. Comparison of serum cystatin C, serum creatinine, measured GFR, and estimated GFR to assess the risk of kidney failure in American Indians with diabetic nephropathy. Am J Kidney Dis. 2013;62:33-41.

14. Ferrannini E, Solini A. SGLT2 inhibition in diabetes mellitus: rationale and clinical prospects. Nat Rev Endocrinol. 2012;8:495-502.

15. Kohan DE, Fioretto P, Tang W, List JF. Long-term study of patients with type 2 diabetes and moderate renal impairment shows that dapagliflozin reduces weight and blood pressure but does not improve glycemic control. Kidney Int. 2014;85:962-71.

16. Barnett AH, Mithal A, Manassie J, et al. Efficacy and safety of empagliflozin added to existing antidiabetes treatment in patients with type 2 diabetes and chronic kidney disease: a randomised, double-blind, placebo-controlled trial. Lancet Diabetes Endocrinol. 2014;2:369-84.

17. Yale JF, Bakris G, Cariou B, et al. Efficacy and safety of canagliflozin in subjects with type 2 diabetes and chronic kidney disease. Diabetes Obes Metab. 2013;15:463-73.

18. Farxiga $^{\circledR} \quad$ (dapagliflozin). Full Prescribing Information, Bristol-Myers Squibb and AstraZeneca, Princeton, NJ, and Wilmington, DE; 2014.

19. Ferrannini E, Ramos SJ, Salsali A, Tang W, List JF. Dapagliflozin monotherapy in type 2 diabetic patients with inadequate glycemic control by diet 
and exercise: a randomized, double-blind, placebo-controlled, phase 3 trial. Diabetes Care. 2010;33:2217-24.

20. Henry RR, Murray AV, Marmolejo MH, Hennicken D, Ptaszynska A, List JF. Dapagliflozin, metformin $\mathrm{XR}$, or both: initial pharmacotherapy for type 2 diabetes, a randomised controlled trial. Int J Clin Pract. 2012;66:446-56.

21. Bailey CJ, Gross JL, Pieters A, Bastien A, List JF. Effect of dapagliflozin in patients with type 2 diabetes who have inadequate glycaemic control with metformin: a randomised, double-blind, placebo-controlled trial. Lancet. 2010;375:2223-33.

22. Bolinder J, Ljunggren $\mathrm{O}$, Kullberg J, et al. Effects of dapagliflozin on body weight, total fat mass, and regional adipose tissue distribution in patients with type 2 diabetes mellitus with inadequate glycemic control on metformin. J Clin Endocrinol Metab. 2012;97:1020-31.

23. Strojek K, Yoon KH, Hruba V, Elze M, Langkilde AM, Parikh S. Effect of dapagliflozin in patients with type 2 diabetes who have inadequate glycaemic control with glimepiride: a randomized, 24-week, double-blind, placebo-controlled trial. Diabetes Obes Metab. 2011;13:928-38.

24. Jabbour SA, Hardy E, Sugg J, Parikh S, For the Study 10 Group. Dapagliflozin is effective as add-on therapy to sitagliptin with or without metformin: a 24-week, multicenter, randomized, double-blind, placebo-controlled study. Diabetes Care. 2014;37:740-50.

25. Wilding JP, Woo V, Soler NG, et al. Long-term efficacy of dapagliflozin in patients with type 2 diabetes mellitus receiving high doses of insulin: a randomized trial. Ann Intern Med. 2012;156:405-15.

26. Leiter LA, Cefalu WT, de Bruin TW, Gause-Nilsson I, Sugg J, Parikh SJ. Dapagliflozin added to usual care in individuals with type 2 diabetes mellitus with preexisting cardiovascular disease: a 24-week, multicenter, randomized, double-blind, placebo-controlled study with a 28-week extension. J Am Geriatr Soc. 2014;62:1252-62.

27. Cefalu WT, Leiter LA, de Bruin TW, Gause-Nilsson I, Sugg J, Parikh SJ. Dapagliflozin's effects on glycemia and cardiovascular risk factors in high-risk patients with type 2 diabetes: a 24-week, multicenter, randomized, double-blind, placebo-controlled study with a 28-week extension. Diabetes Care. 2015;38:1218-27.
28. Levey AS, Coresh J, Greene T, et al. Using standardized serum creatinine values in the modification of diet in renal disease study equation for estimating glomerular filtration rate. Ann Intern Med. 2006;145:247-54.

29. Inzucchi SE, Lipska KJ, Mayo H, Bailey CJ, McGuire DK. Metformin in patients with type 2 diabetes and kidney disease: a systematic review. JAMA. 2014;312:2668-75.

30. Delanaye P, Cavalier E, Moranne O, Lutteri L, Krzesinski JM, Bruyere O. Creatinine-or cystatin C-based equations to estimate glomerular filtration in the general population: impact on the epidemiology of chronic kidney disease. BMC Nephrol. 2013;14:57.

31. Dharnidharka VR, Kwon C, Stevens G. Serum cystatin $\mathrm{C}$ is superior to serum creatinine as a marker of kidney function: a meta-analysis. Am J Kidney Dis. 2002;40:221-6.

32. Peralta CA, Katz R, Sarnak MJ, et al. Cystatin C identifies chronic kidney disease patients at higher risk for complications. J Am Soc Nephrol. 2011;22:147-55.

33. Buysschaert M, Joudi I, Wallemacq P, Hermans MP. Performance of serum cystatin-C versus serum creatinine in subjects with type 1 diabetes. Diabetes Care. 2003;26:1320.

34. Christensson AG, Grubb AO, Nilsson JA, Norrgren K, Sterner G, Sundkvist G. Serum cystatin C advantageous compared with serum creatinine in the detection of mild but not severe diabetic nephropathy. J Intern Med. 2004;256:510-8.

35. Krolewski AS, Warram JH, Forsblom C, et al. Serum concentration of cystatin $\mathrm{C}$ and risk of end-stage renal disease in diabetes. Diabetes Care. 2012;35:2311-6.

36. Tsai CW, Grams ME, Inker LA, Coresh J, Selvin E. Cystatin C- and creatinine-based estimated glomerular filtration rate, vascular disease, and mortality in persons with diabetes in the U.S. Diabetes Care. 2014;37:1002-8.

37. Schottker B, Herder C, Muller $H$, Brenner $H$, Rothenbacher D. Clinical utility of creatinine- and cystatin C-based definition of renal function for risk prediction of primary cardiovascular events in patients with diabetes. Diabetes Care. 2012;35:879-86. 
38. de Boer IH, Katz R, Cao JJ, et al. Cystatin C, albuminuria, and mortality among older adults with diabetes. Diabetes Care. 2009;32:1833-8.

39. Inker LA, Schmid $\mathrm{CH}$, Tighiouart $\mathrm{H}$, et al. Estimating glomerular filtration rate from serum creatinine and cystatin C. $\mathrm{N}$ Engl J Med. 2012;367:20-9.
40. Johnsson KM, Ptaszynska A, Schmitz B, Sugg J, Parikh SJ, List JF. Vulvovaginitis and balanitis in patients with diabetes treated with dapagliflozin. J Diabetes Complications. 2013;27:479-84. 